\title{
Experimental study on frost area of peat soil roadbed settlement defor- mation
}

\author{
Han Yumin ${ }^{1, a}$, Shi Xiaoxing ${ }^{2, b}$ \\ ${ }^{1}$ Baicheng Normal University, Baicheng, Jilin, China \\ ${ }^{2}$ Baicheng Normal University, Baicheng, Jilin, China \\ ahanyumin9916@163.com, bxiaoxing 8162@163.com
}

\begin{abstract}
Keywords: seasonal frozen region; peat soil; subgrade; settlement; test
Abstract. Aiming at the problems of disease and adverse geological section of peat soil, the entity test project, the settlement deformation law of peat soil roadbed is analyzed, and the theoretical calculation results and the actual monitoring results of test section compares the total longitudinal settlement. Due to changes in layer thickness, as peat soil, lead to obvious differences in time on the settlement of turfy soil; peat soil foundation settlement amount and thickness of peat land basic positive proportion; according to the long-term observation, the test project focused on monitoring and sampling survey, data analysis and sorting, visible different turfy soil ground treatment measures have advantages and disadvantages. Therefore, should be combined with the climate characteristics in the actual project, for the completion of prediction of peat land area used for roadbed settlement provides theoretical guidance and reasonable solution of peat soil roadbed.
\end{abstract}

\section{Introduction}

Based on the diseases and hiddden troubles in the adverse geological sites of peat soil, the authors conduct a theoretical analysis on the settlement and deformation rules of the peat soil roadbed by relying on the entity test engineering, and also compare the theoretical calculation results with the actual observation results of the total longitudinal settlement of the test road. The obtained results give the theoretical guidance to the estimation on the settlement after the completion of the roadbed contruction of the peat soil area and also the reasonable determination of the solution to process the peat soil roadbed.

\section{Introduction to test road}

In the test engineering of the peat soil roadbed, large numbers of observation instruments are buried to implement multiple test observations such as the total settlement, lamination settlement, lateral suface, vertical displacement, deep lateral displacement, and Pore water pressure, water level and soil pressure. The test-road horizontal alignment and vertical section are designed based on the first-class highway standards. Also, the radius of the horziontal curve of one section in the test road is $1000 \mathrm{~m}$; the radiuses of two vertical curves are $19000 \mathrm{~m}$ and $40000 \mathrm{~m}$ respectively, and the largest longitudinal slope is $1.52 \%$. The specifics can be seen in the road' $\mathrm{s}$ longitudinal map.

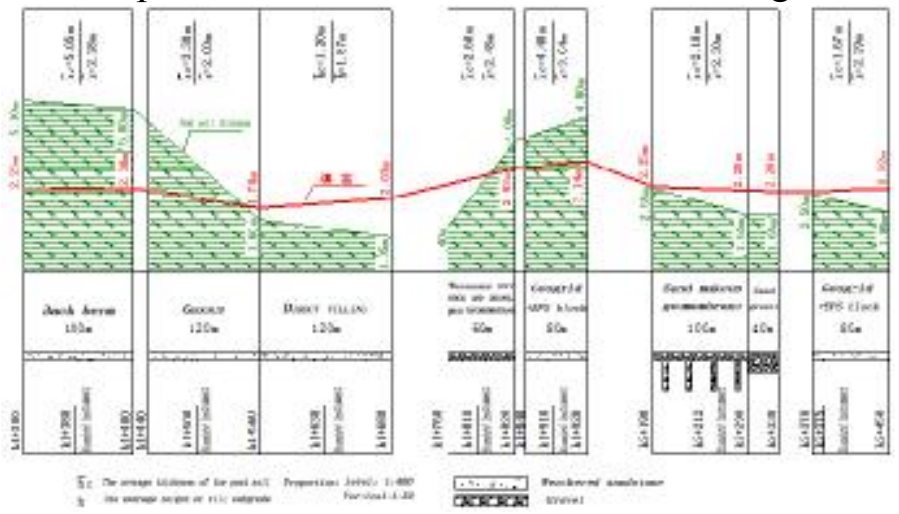

Figure 1 Test Engineering vertical layout 


\section{Test and indenting}

Generally speaking, the final settlement of the roadbed can be divided into three parts according to the causes of their formation.

First, the immediate settlement is produced within a very short time when the load is just added. For the saturated soil roadbed, the water in it is still not be drained;the settlement is mainly caused by the soil-body lateral deformaion. Now, however, the soil body has no change in its volume. Second, the primary consolidation settlement is called as consolidation settlement as well. It mainliy refers to the seepage consodation result generally when the pore water of the saturated cohesive soil in the load action is squeezed out. In other words, the pore water pressure is dissipated with a gradual step, making the soil volume compressed, and hence the seepage consolidation is caused. Third, the secondary consolidation settlement is mainly caused from the soil-grain surface to combine water film and subsequently generate creep deformation, and will settle at an extremely slow speed over time. Therefore, the roadbed' $s$ final settlement shall be the sum of the above three, which is expressed with $\mathrm{S}=\mathrm{SD}+\mathrm{SC}+\mathrm{Ss}$. For the calculation of the immediate settlement, the elasic theory is usually used. However, for the consolidation settlement, the layer-wise summation method is often applied.

\section{Settlement Calculation Methods}

\section{Layer-wise Summation Method}

The soil layers within the thickness of the compression layer are divided into multiple thin horizontal layers. Meanwhile, it can be assumed there are no lateral expansions, and the settlements of all divided layers in the roadbed center-axis can besummed up finally as the fundamental finally settlement.

It can be assumed that the thickness of certain horizontal soil is $\mathrm{h}$, and the compression deformation is s, As the soil layers are assumed to have no lateral expansions, and the compression of the soil layers are thouught as the reducation of the pore volume, the s can be obtained according to the changes in the pore height of the soil column volume of a unit section and ite proportion and the following equation is established.

$$
s=\frac{e_{1}-e_{2}}{1+e_{1}} h
$$

Based on the definition of the compressibility coefficient $a=\left(e_{1}-e_{2}\right) / \sigma_{z}$ namely, $e_{1}-e_{2}=a \sigma_{z}$ which can be Substituted into the above equation to gain the equation below.

$$
s=\frac{a}{1+e_{1}} \sigma_{z} h=\frac{\sigma_{z}}{E_{s}} h
$$

In th e above equation, a and Es respectively are the compressibility coefficient and compressibility modulus of pressure increasing from, which can be obtained from the compression curve (the unit is Kpa). Is the average effective gravity pressure of the horizontal soil layer (i.e. the efficiencyweighted average value between top surface and bottom surface, and the unit is $\mathrm{KPa}$ ) is the effectively average additional pressure in the fundamental center axe of the horizontal soil layer(i. e. the average value of the effectively additional pressure between top surface and bottom surface, and the unit is $\mathrm{KPa}$ ). el is the void ratio before the soil layers are compressed can be obtained from the compression curve. His the height of the horizontal soillayer, and the unit is $\mathrm{cm}$ ). 
The consolidation settlement of the soft soil foundation is gradually completed. over time. Thus, at different consolidation times, the settlements are different. To research the changing process of the settlements and the increasing process of the ground base intensity over time. it is necessary to calculate the consolidation degree $(\mathrm{U})$ of the ground base. The consolidation degree of the ground base generally includes the vertical consolidation and horizontal consolidation. Terzaghi. seepage consolidation differential equation is applied to the calculations of the two types of consolidation degree.

$$
\frac{\partial u}{\partial t}=C_{h}\left(\frac{\partial^{2} u}{\partial r^{2}}+\frac{1}{r} \frac{\partial u}{\partial r}\right)+C_{v} \frac{\partial^{2} u}{\partial z^{2}}
$$

Under the immediate loads, the condition theory without consolidation theory without vertical drained ground base are as shown below Initial condition: $\mathrm{u} \mid \mathrm{t}=0 \mathrm{u} 0$

Boundary conditions: $\mathrm{u}\left|\mathrm{z}=0=0 ; \quad \frac{\partial u}{\partial z}\right|_{H=0}=0$

In the above, $\mathrm{u} 0$ is the initial pore water pressure; $\mathrm{H}$ is the height of the compression layer (it is single-side drainage when $\mathrm{Z}=\mathrm{H}$ ).

$$
\left.u(z, t)=\sum_{m=1}^{\infty} \frac{2}{H} \int_{0}^{H} u_{0} \sin \frac{M_{z}}{H} d z\right) \sin \frac{M_{z}}{H} e^{-M^{2} T_{v}}
$$

In the above, $M=(2 m-1) \pi / 2 \mathrm{Tr}$ is time factor, $T_{v}=C_{v} t / H^{2}$ if $\mathrm{u} 0$ is homogeneously distributed within the whole compression layer, it is a constant, and the following equitation can be estalished.

$$
u(z, t)=u \sum_{m=1}^{\infty} \frac{2}{M} \sin \frac{M_{z}}{H} e^{-M^{2} T_{v}}
$$

The vertical average pore water stress of the whole compression layer at the "t"time is $u$, and its vertical average consolidation degree is Uv, which can be expressed tespectively below.

$$
\begin{aligned}
& \bar{u}(t)=\frac{1}{H} \int_{0}^{H} u d z=u_{0} \sum_{m=1}^{\infty} \frac{2}{M^{2}} e^{-M^{2} T_{v}} \\
& \bar{U}_{v}(t)=\frac{u_{0}-\bar{u}(t)}{u_{0}}=1-\sum_{m=1}^{\infty} \frac{2}{M^{2}} e^{-M^{2} T_{v}}
\end{aligned}
$$

As for engineering applications, the enough accuracy can be obtained by selecting the first item, namely,

$$
\bar{U}_{v}(t)=1-\frac{8}{\pi^{2}} e^{-M^{2} T_{v}}
$$

The solution to the horizontal consolidation equation under the equal vertical strain and free vertical conditions is.

$$
u=\frac{u_{0}}{r_{e}^{2} F(n)}\left[r_{e}^{2} \ln \left(\frac{r}{r_{w}}\right)-\frac{r^{2}-r_{w}^{2}}{2}\right] e^{\lambda}
$$

In this equation, $\mathrm{u}$ is the excess pore water pressure;re is the equivalent radius of soil column (de/2);rw is the radius of drain $(\mathrm{dw} / 2)$;

$$
\begin{aligned}
& \lambda=-\frac{8 T_{h}}{F(n)} ; T_{h}=\frac{C_{h} t}{d_{e}^{2}} ; n=d_{e} / d_{w} ; \\
& F(n)=\frac{n^{2}}{n^{2}-1} \ln (n)-\frac{3 n^{2}-1}{4 n^{2}}
\end{aligned}
$$

Besides, can be decided per. $d_{e}=\sqrt{\frac{4}{\pi}} l=1.13 l$.

In this equation, de is the effective diameter of sand drain:I is the space between sand drains ( $\mathrm{I}=1$. $0 \mathrm{~m}$ in the test engineering). Therefore, only the horizontal consolidation degree at the radial flow is 
taken into account, which is $\bar{U}_{r}(t)=1-e^{-\frac{8 T_{h}}{F(n)}}$. Then, the vertical and radial drains consolidation degrees can be thought comprehensively and their calculation equation is:

$$
\bar{U}_{r v}=1-\left(1-\bar{U}_{v}\right)\left(1-\bar{U}_{r}\right)=1-\frac{8}{\pi^{2}} e^{-\left(\frac{8}{F(n)} \frac{C_{h}}{d_{e}^{2}}+\frac{\pi^{2}}{4} \frac{C_{v}}{H^{2}}\right) t}
$$

\section{Calculation of test road subgrade settlement theory}

As for the $\mathrm{K} 1+400 \sim \mathrm{K} 2+500$ text road. and based on the drill hole sampling. the authors in the study calculate the settlements of 16 cross sections and 46 drill holes. Except the K2+140 and $\mathrm{K} 2+450$ cross sections only having two drill holes. the others all have three ones respectively. The soil layers exposed by drill holes mainly are the peat soil layer. silty clay layer and sand layer. On the $\mathrm{K} 1+400$ and $\mathrm{K} 1+680$ cross section, it can be seen that a sand sheet is between silty clay layers the two cross sections have five roadbeds.

Base on $\sigma_{z}=0.2 \sigma_{c z}$ the lower limit of the compression layer can be decide. Through the layerwise summation method. it can be assumed that roadbed is filled to be $2 \mathrm{~m}$ at average all actual soil layer settlements and the total settlements of all roads represented by all holes can be calculate in theory. providing a reference for the final determination of the feasible processing solution and the evaluation on the processing results. According to the calculated roadbed centers of all soil layers as well as the longitudinal primary consolidation settlement, secondary consolidation settlement, immediate settlement and total

Settlement at the two sides, the settlement space relationship curve can be drawn respectively, which are as shown in figure $2 \sim 11$. In these figures, the horizontal ordinate represents the mileage of the vertical section of the road, and the longitudinal coordinate is the settlement of the roadbed.

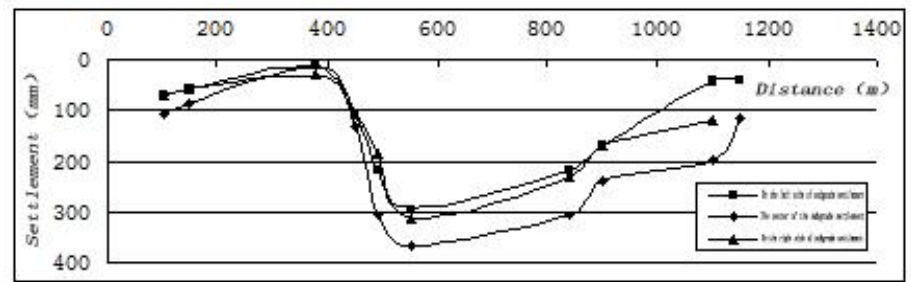

Figure 2. The primary consolidation settlement space relationship curve of the $\mathrm{K} 1+300-\mathrm{K} 2+450$ roadbed vertical section peat soil

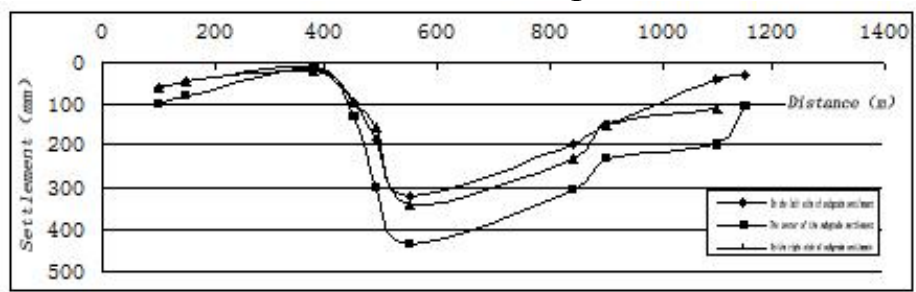

Figure 3. The immediate settlement space relationship curve of the $\mathrm{K} 1+300-\mathrm{K} 2+450$ roadbed vertical section peat soil

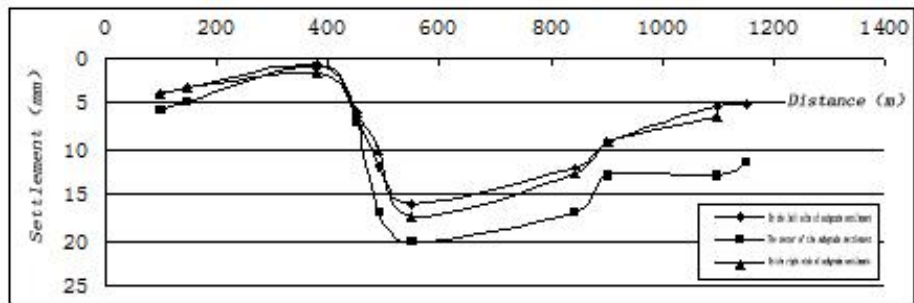

Figure 4 . The secondary consolidation settlement space relationship curve of the K1+300-K2+450 roadbed vertical section peat soil 


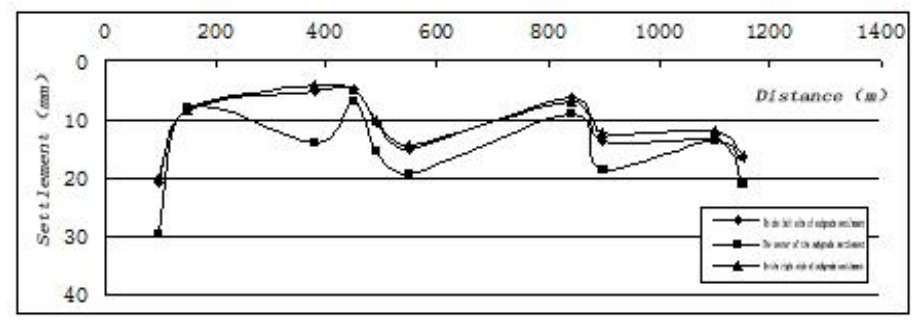

Figure 5. The primary consolidation settlement space relationship curve of the $\mathrm{K} 1+300-\mathrm{K} 2+450$ roadbed vertical section silty clay

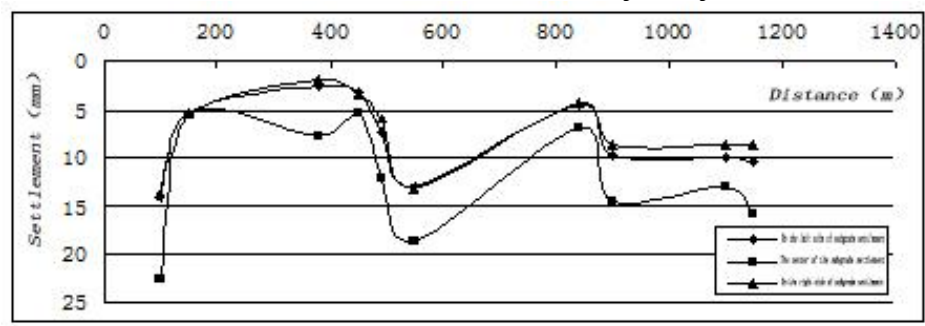

Figure 6 . The immediate consolidation settlement space relationship curve of the K1+300$\mathrm{K} 2+450$ roadbed vertical section silty clay

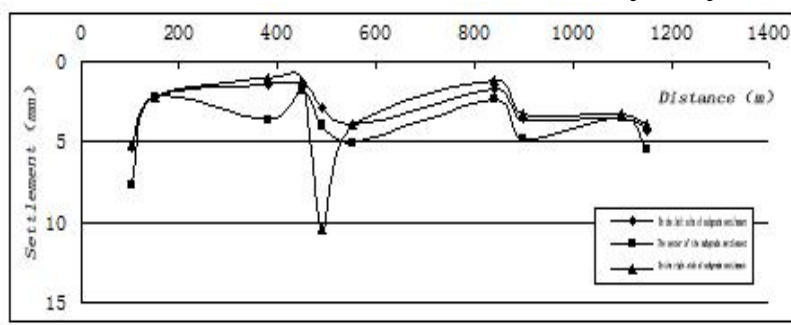

Figure 7 . The secondary consolidation settlement space relationship curve of the K1+300-K2+450 roadbed vertical section silty clay

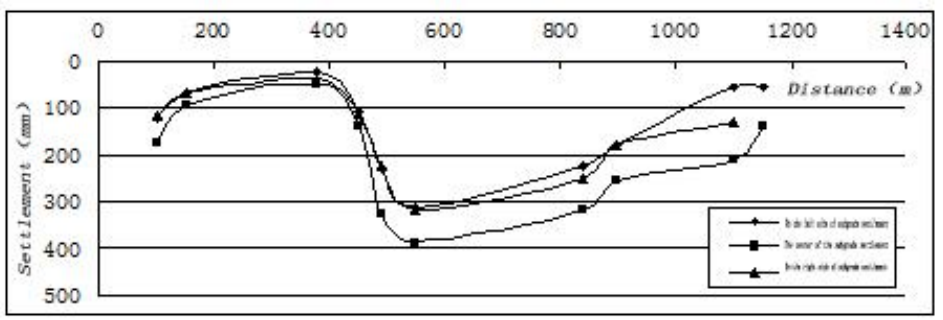

Figure 8 . The primary consolidation settlement space relationship curve of the $\mathrm{K} 1+300-\mathrm{K} 2+450$ roadbed vertical section

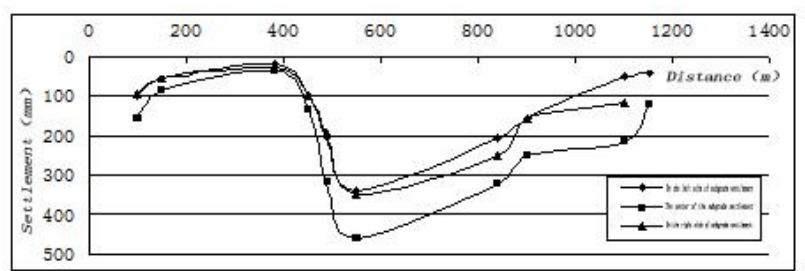

Figure 9. The total immediate settlement space relationship curve of the $\mathrm{K} 1+300-\mathrm{K} 2+450$ roadbed vertical section

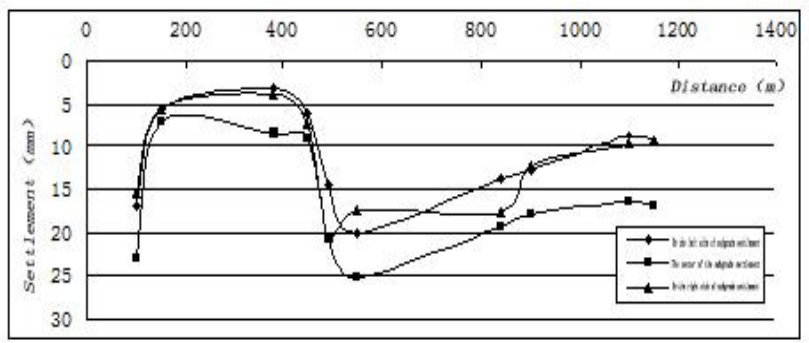

Figure 10 . The total secondary consolidation settlement space relationship curve of the K1+300-

$\mathrm{K} 2+450$ roadbed vertical section 


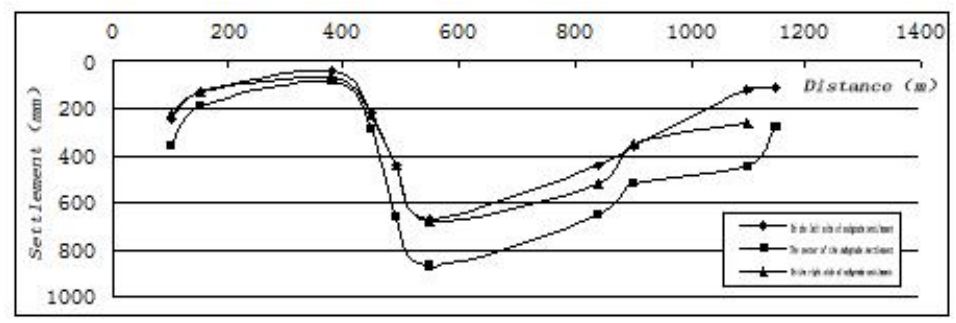

Figure 11. The total settlement space relationship curve of the $\mathrm{K} 1+300-\mathrm{K} 2+450$ roadbed vertical section

From the above figures, it can be seen that the roadbed center axes and the settlements at two sides are similar to the settlement trend of the peat soil layer. In other words, the roadbed settlement is controlled by the settlement of the peat soil layer; the settlement in the road with thick peat soil layer is also relatively large ; the curve slightly changes in the road with thick silty clay layer, but keeps unchanged basically. From the figures, it is not hard to discover the K1+850 (corresponding to $500-600 \mathrm{~m}$ distance) settlement is large, and also the peat soil layer at the $\mathrm{K} 1+850$ place is relatively the thickest $(3.1-3.5 \mathrm{~m})$. On the contrary, the $\mathrm{K} 1+600$ (corresponding to about $300 \mathrm{~m}$ distance) is the place where the peat soil is the thinnest among all drill holes (the corresponding silty clay layers are very thin), and the settlement is the smallest as well

\section{Analysis on the monitoring of the roadbed settlement}

The table 1 and figure 12 summarize the disposal solutions of all road sections in the test engineering changing along the spaces and the comparison on theoretical calculations. It can be known that the difference of the peat

Soil roadbdined in the buried depth along the longitudinal direction makes the engineering generate different total consolidation settlements under the actually-filling load action. compared with theoretical calculation of the layer-wise summation method, it can be seen that the total consolidation settlements of the $\mathrm{K} 1+630$ actually-filling representative section, which are monitored actually in the monitoring period, exceed theoretical calculation ; and the other disposal solution representative sections all are lower than theoretical calculation. For example, the total consolidation settlements of the $\mathrm{K} 1+810, \mathrm{~K} 1+910, \mathrm{~K} 2+375$ representative sections which are monitored actually are only 80 $83 \%$ of theoretical calculation. These suggest that the used sand and broken stone mat base, composite geomembrane, plastic foam, geogrid, replacement filling and other disposal technologies are feasible for the improvement of the anti-deformation abilities of roadbed, and also their effects are approximate. As for the back berm, and sand disposal solution, their realities and theoretical are quite close and are within the range of the theoretical calculation.

Table 1 test sections of engineering settlement along the spatial variation and theoretical estimation comparison

\begin{tabular}{|c|c|c|c|c|}
\hline Representative sections & Processing measures & $\begin{array}{c}\text { Practical } \\
\text { monitoring } \\
(\mathrm{mm})\end{array}$ & $\begin{array}{c}\text { Theoretical } \\
\text { calculation } \\
(\mathrm{mm})\end{array}$ & $\begin{array}{c}\text { Comparisonof theory and } \\
\text { Practicetheory and Practice } \\
(\mathrm{mm})\end{array}$ \\
\hline $\mathrm{K} 1+380$ & loading berm & -391 & -419 & -28 \\
\hline $\mathrm{K} 1+500$ & geogrid & -192 & -171 & 21 \\
\hline $\mathrm{K} 1+630$ & direct filling & -161 & -112 & 49 \\
\hline $\mathrm{K} 1+810$ & Gravelweathered softrock + earthwork & -611 & -730 & -119 \\
\hline $\mathrm{K} 1+910$ & Geogrid +EPS block & -734 & -826 & -92 \\
\hline $\mathrm{K} 2+212$ & Sand pile and composite geotextile & -529 & -533 & -4 \\
\hline $\mathrm{K} 2+300$ & Sand gravel & -485 & -590 & -105 \\
\hline $\mathrm{K} 2+375$ & Geogrid +EPS plate & -559 & -640 & -81 \\
\hline
\end{tabular}




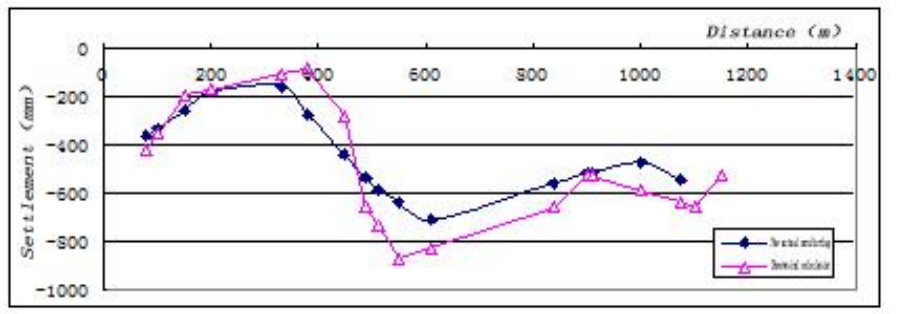

Figure 12 test engineering section $\mathrm{K} 1+300-\mathrm{K} 2+500$ longitudinal settlement curve

\section{Conclusion}

First, due to the changes of the peat soil roadbed thickness and layered structure, there are obvious differences in the time variation of the pest soil roadbed settlement; the peat soil layer is thin ; the consolidation degree, at the place where the sand layer is buried shallowly, increases quickly; the consolidation time is short;the drainage rate, at the place where the peat soil layer is deeper, will be slower, and the consolidation degree increases slowly. The theoretical calculations suggest the consolidation degree reaches over $90 \%$ in 180 days; the isoline of the consolidation degree becomes highly sparse in 365 days, the settlement is stable and the consolidation is completed.

Second, the settlement of the peat soil roadbed basically has a positive proportion relationship with the thickness of the peat soil roadbed. Namely the deeper the peat soil roadbed is, the larger its settlement will be and otherwise it is smaller. The primary consolidation settlement and immediate settlement constitute the main parts of the total settlement The secondary consolidation settlement is highly small, but its proportion will increase along with the increase of the thickness of the silty clay constituting the roadbeds.

Third after the actual monitoring on the change of the settlements along spaces and the comparison on the theoretical calculation, it is found that the fitting condition of the two is good, and their difference is between 11.9 to $4.9 \mathrm{~cm}$.

According to the long_term observation and key monitoring on the test engineering and the analysis and classification on the date obtained from sampling surveys, it can be seen that different peat soil roadbed disposal measures have their advantages and disadvantages. Therefore, in the actual engineering, it is necessary to combine the regional climate characteristics, think of the protection on the peat soil groundwork wetland resources, and make specific evaluations on all kinds of disposal solutions, providing proposed proposed projects with judgment, selection and strategic decision.

\section{References}

[1] LiuYanling. Reasearch on the Settlement and Deformation Characterics of Peat Soil Roadbed[D]. Jilin University, 2006.

[2] Zhang Liujun, Wang Fusheng, Liu Jiandu. Highway Soft Soil Foundation Processing Technology [M]. China Communications Press, 2002, 9, 1st Editiong:2 111.

[3] Gao Dazhao, Yuan Juyun. Soil Geology and Soil Mechanics [M]. China Communications Press, 2004, 2, 3rd Edition. 